\title{
The role of imaging in percutaneous laser ablation therapy of small breast cancers
}

\author{
Barbara S Schwartzberg* \\ Sarah Cannon Research Institute at Rose Medical Center, Western Surgical Care P.C., USA
}

Percutaneous laser ablation therapy is a potential nonsurgical minimally invasive alternative to lumpectomy in the treatment of small, early stage breast cancers. Focal tumor destruction is accomplished following insertion of a laser fiber into the targeted cancer center. The intense light created by the laser fiber is converted to thermal energy, which heats the surrounding tissue. Immediate tissue destruction is caused by direct heat injury. Secondary tumor cell damage occurs by indirect heat injury, which produces progressive tissue damage in the form of tissue vaporization, microvascular damage, tissue necrosis, and immune cell activation.

The increasingly important role of imaging in percutaneous laser ablation of breast cancers is four-fold. First, increased use of screening mammography and ultrasound allows for detection of smaller early stage breast cancers. In the United States, breast cancers with good prognoses (Grade 1, estrogen receptor and/or progesterone receptor positive) represent $38.2 \%$ of women at least 40 years of age [1]. The tumor biology of these small cancers may create radiographic changes which allow for early detection via screening. These cancers represent a group of patients which may be cured with less aggressive intervention.

Percutaneous ablation techniques rely on image guidance to accurately target tumors prior to initiation of procedures. Ultrasound guidance has been accurate in targeting breast cancers prior to laser ablation [2]. MRI guided targeting for radiofrequency ablation of breast cancers [3] and laser ablation of other solid organ cancers has been reported [4]. Dowlatshahi and colleagues reported use of stereotaxis in placement of an 805 nanometer nominal wavelength laser diode source in 56 patients with early stage breast cancer [5]. Stereotactic visualization was aided by placement of metallic markers around the tumor before initiation of treatment.

All of these techniques report difficulties with documentation of ablation procedure completeness when measured by changes in imaging. For example, once cryoablation treatment has commenced, ultrasound shows only the surface of the cryotherapy iceball while the area beneath the surface is not clearly visible. The hyperechogenicity of treated breast tissue and the ultrasonographic shadowing makes it difficult to differentiate between ablated tissue and residual tumor. This makes ultrasound more difficult as a real-time monitor of treatment progress. Dowlatshahi solved this problem with creation of a laser

Copyright: $@ 2018$ Schwartzberg BS. This is an open-access article distributed under the terms of the Creative Commons Attribution License, which permits unrestricted use, distribution, and reproduction in any medium, provided the original author and source are credited. system source (Novilase ${ }^{(\mathrm{R})}$ Laser Therapy, Novian Health, Chicago, Illinois) which monitored treatment progress by measurement of temperatures at the periphery of the desired ablation zone [5]. Temperature probes placed at the tumor periphery via image guidance monitored tissue temperature changes, making laser ablation independent of breast tissue density, vascularity, treatment time, energy delivered, or anesthetic injection. Immediate cell death occurred when cells were heated to $60^{\circ} \mathrm{C}$.

Detection of residual tumor by post-ablation imaging must be equivalent to post-surgical pathology evaluation for laser ablation to be a suitable alternative to lumpectomy. Diagnostic imaging techniques which include ultrasound, computed tomography and magnetic resonance imaging have been investigated [6]. MRI has had the greatest success in accomplishing this goal. Post-cryoablation detection of residual tumor by MRI has been reported with a negative predictive value of $92 \%$ [7].

Percutaneous laser ablation, combined with state of the art imaging, has the potential to replace surgical excision as a new gold standard in the treatment of early stage breast cancer. Modifications in imaging and techniques will further define this therapy.

\section{References}

1. Lannin DR, Wang S (2017) Are Small Breast Cancers Good because They Are Small or Are They Small because They Are Good? N Engl J Med 376: 2286-2291. [Crossref]

2. van Esser S, Stapper G, van Diest PL (2009) Ultrasound-Guided Laser-Induced Thermal Therapy for Small Palpable Invasive Breast Carcinomas: A Feasibility Study Ann Surg Oncol 16: 2259-2263. [Crossref]

3. van den Bosch M, Daniel B, Rieke V (2008) MRI-Guided Radiofrequency Ablation of Breast Cancer: Preliminary Clinical Experience. J Magn Reson Imaging 27: 204-208. [Crossref]

4. Stafford RJ, Fuentes D, Elliott AA (2010) Laser-Induced Thermal Therapy for Tumor Ablation. Crit Rev Biomed Eng 38: 79-100. [Crossref]

5. Dowlatshahi K, Francescatti DS, Bloom KJ (2002) Laser Therapy for Small Breast Cancers. Am J Surg 184: 359-363. [Crossref]

6. Mumtaz H, Hall-Craigs MA, Wotherspoon A (1996) Laser Therapy for Breast Cancer: MR Imaging and Histopahologic Correlations. Radiology 200: 651-658. [Crossref]

7. Simmons RM, Ballman KV, Cox C (2016) A Phase II Trial Exploring the Success of Cryoablation Therapy in the Treatment of Invasive Breast Carcinoma: Results from ACOSOG (Alliance) Z1072. Ann Surg Oncol 23: 2438-2445. [Crossref]
*Correspondence to: Barbara S. Schwartzberg, Sarah Cannon Research Institute at Rose Medical Center, Western Surgical Care P.C., Denver, Colorado 80220, USA, Tel: 303-320-7826; E-mail: scmibs@gmail.com

Received: March 02, 2018; Accepted: March 19, 2018; Published: March 22 2018 